\title{
Antibiotic Prescription in Febrile Children: A Cohort Study during Out-of-Hours Primary Care
}

\author{
Gijs Elshout, MD, Marijke Kool, MD, Johannes C. Van der Wouden, PhD, \\ Henriëtte A. Moll, MD, PhD, Bart W. Koes, PhD, and Marjolein Y. Berger, MD, PhD
}

Background: Fever is common in children and often self-limiting, nevertheless antibiotics are frequently prescribed. We determined how often antibiotics were prescribed in children presenting with fever at a family physicians' out-of-hours service and established the children's signs and symptoms related to antibiotic prescriptions.

Patients: Children aged 3 months to 6 years with fever as the main reason for contact.

Results: Of the 443 included children, 322 children had a face-to-face contact at the out-of-hours service. Of these, $117(36.3 \%)$ were prescribed antibiotics, that is, $26.5 \%$ of the total study population. Concerned parents $(0 R, 2.02 ; 95 \%$ CI, 1.06-3.58), ill appearance $(3.26 ; 1.30-8.20)$, earache resulting in altered behavioral or sleeping patterns $(2.59 ; 1.06-6.30)$, signs of throat infection $(2.37$; 1.35 $4.15)$, and decreased urine production $(2.00 ; 1.17-3.41)$ were positively associated with antibiotic prescription. A negative association was found for age 3 to 6 months $(0.17 ; 0.03-0.74)$ and temperature (0.52; 0.37-0.71).

Conclusions: Antibiotics were prescribed in 1 out of 4 febrile children whose parents contacted the out-of-hours service. Items associated with antibiotic prescription provide insight into the family physicians' decision-making process when assessing children with fever. These can be used as targets for strategies to diminish antibiotic prescription. (J Am Board Fam Med 2012;25:810-818.)

Keywords: Antibiotics, Child, Family in Family Medicine, Family Medicine, Fever, Infectious Diseases, Pediatrics, Primary Health Care

Fever in children is a frequent reason for parents to contact a primary care physician. ${ }^{1}$ It is a common symptom in children, often caused by benign in-

This article was externally peer reviewed.

Submitted 7 November 2011; revised 11 April 2012; accepted 23 April 2012.

From the Department of General Practice, University Medical Center Groningen, Groningen, The Netherlands; Erasmus MC Rotterdam; and Erasmus MC-Sophia Children's Hospital, Rotterdam, The Netherlands.

Funding: This study was supported by The Netherlands Organisation for Health Research and Development (ZonMw), grant number: 42000012. ZonMw had no part in the study design or data analyses, and the researcher performed the described study in full independence.

Conflict of interest: This study was supported by The Netherlands Organisation for Health Research and Development (ZonMw), grant number: 42000012. The authors had no financial relationships with any organizations that might have an interest in the submitted work in the previous 3 years. The authors had no other relationships or activities that could appear to have influenced the submitted work.

Corresponding author: Marjolein Y. Berger, MD, PhD, University Medical Center Groningen, Department of General Practice, Groningen, The Netherlands (E-mail: m.y.berger@ med.umcg.nl). fections with no need for medical intervention. Nevertheless, because approximately $1 \%$ of the children with an acute infection have a serious infection, ${ }^{2}$ there is a small risk for underlying serious infections that need medical treatment.

In The Netherlands, the management of children with fever in primary care is based on the guideline for the management of febrile children of the Dutch College of General Practitioners (NHG). ${ }^{3}$ This guideline does not recommend routine use of antibiotics in children with fever without an apparent source. The US guideline for children with fever without a source does have some recommendations about antibiotic treatment, for example, starting empirical antibiotics in children aged $>1$ month when they are not meeting the predefined low-risk criteria for a serious bacterial infection. ${ }^{4}$ However, these recommendations are subject to debate. ${ }^{4,5}$

In case of fever with a focus, Dutch treatment recommendations can be found in several disease- 
specific guidelines, most of which are relatively conservative concerning the use of antibiotics. ${ }^{6-9}$ When compared with the US guidelines, the Dutch guidelines for sinusitis and nonspecific cough illness/bronchitis are comparable in their recommendations for antibiotic prescription. ${ }^{10,11}$ The recommendations for antibiotic treatment for acute otitis media (AOM) and pharyngitis are in the Dutch guidelines more stringent than in the United States. ${ }^{12,13}$ For instance, in The Netherlands, AOM in children aged 6 months to 2 years is only treated with antibiotics under certain conditions (ie, risk factors for complications or severe illness), whereas in the United States for all these children, antibiotic treatment is recommended. Another example is that in The Netherlands pharyngitis is not tested for a group A streptococcus infection, because it is thought not to make a difference in the family physician's decision-making. In the United States, however, it is common practice to test for a group A streptococcus infection, because it is thought to influence the decision-making process. All these recommendations take into account patient characteristics (eg, age, anatomic deformities), signs and symptoms (eg, otorrhea, no improvement after 3 days), and consider the possible risk of (progression to) a serious bacterial infection, but also that antibiotics may reduce the duration and severity of the disease. ${ }^{14,15}$ Because serious infections are rare in primary care, ${ }^{2}$ the latter reason may be applied more often. In addition, other (not medically based) considerations may play a role in the family physicians' decision to prescribe antibiotics (eg, assuming that the patient or the parents expect antibiotics). ${ }^{16-18}$

In the last decades, the number of inappropriate prescriptions of broad-spectrum antibiotics has increased in The Netherlands. ${ }^{19}$ Another Dutch study reported an overall antibiotic prescription rate of $35 \%$ for acute respiratory tract infections among preschool children in primary care. ${ }^{20}$ Overuse of antibiotics is an important factor in the development of bacterial resistance, and therefore prevention of unnecessary prescription is desirable. $^{21,22}$ Therefore, it is important to monitor the frequency of antibiotic prescriptions and to critically evaluate the signs and symptoms on which physicians base their decision to prescribe antibiotics. Appropriate consideration of these signs and symptoms may lead to better founded and, consequently, diminished antibiotic prescriptions.
The present study evaluates the frequency of antibiotic prescriptions in children presenting with fever at a family physicians' out-of-hours service and assesses the patient characteristics associated with these prescriptions.

\section{Methods}

This cohort study was performed at a family physicians ' out-of-hours service in Rotterdam, a large multiethnic city in The Netherlands. This out-ofhours service covers an area encompassing approximately 300,000 inhabitants.

\section{Study Procedures}

Between December 2004 and January 2006 (during Monday through Thursday evenings), consecutive children were included if they were aged between 3 months and 6 years and presented with fever as stated by the parents. Fever had to be the main contact reason. Children were excluded if communication in Dutch was impossible $(\mathrm{n}=151)$; if the child had already been enrolled in this study in the past 2 weeks $(\mathrm{n}=11)$; if the child was admitted to the hospital directly after visiting the out-of hours service $(n=19)$; if they presented to the out-of hours service already having antibiotics for this condition $(\mathrm{n}=44)$; or if the parents declined to give informed consent $(n=618)$.

When parents contacted the out-of-hours service by telephone concerning their febrile child, the receptionists performed the standard triage based on the triage guideline of the NHG. ${ }^{23}$ In addition, for the present study, the receptionists completed a questionnaire related to triage items. Based on this triage, parents received either telephone advice or the advice to attend the out-of-hours service (consultation) or a home visit by a family physician was arranged. The family physicians were free to prescribe treatments of their own choice or to refer the patient. It should be noted that the out-of-hours service, in that time, had no access to the child's regular family physician's medical record. Therefore, the out-of-hours service had no structured overview of the medical history of the patients. The records made at the out-of-hours service are digitally send to the children's own family physician the next day.

\section{Baseline and Outcome Measurements}

For the purpose of this study, for all children, an additional home visit by a trained research nurse 
was arranged within 24 hours of inclusion. Using a structured questionnaire, the research nurse recorded demographic data, signs and symptoms that were present at the time of contact with the outof-hours service, physician contacts, and prescribed medication as reported by the parents; in addition, a standardized physical examination (including rectal temperature) was performed.

Tachypnea was defined as an elevated respiratory rate, taking age into account as recommended by the guideline of the National Institute for Health and Clinical Excellence. ${ }^{24}$ The Yale Observation Scale score was part of the structured physical examination. The Yale Observation Scale has a 6-item score to predict the severity of illness in febrile children. ${ }^{25}$ Ill appearance was judged by the research nurse during the home visit. Duration of illness was determined in days and calculated using the date of contact and the date of the first signs and symptoms of illness.

The Dutch Central Committee on Research Involving Human Subjects approved the study.

\section{Statistical Analysis}

The main outcome measure was antibiotic prescription (yes/no) by the family physician at the out-of-hours service as reported by the parents. Patient characteristics and frequency of antibiotic prescription were analyzed using descriptive statistics. Variables possibly related to antibiotic prescription were analyzed using bivariate and multivariate logistic regression. The choice of variables and the presumed associations were based on the recommendations of national and international guidelines. ${ }^{3,6-9,24}$ All variables were bivariately tested, and the variables selected for multivariate analysis were based on their assumed relationship with antibiotic prescription. To allow for unexpected predictors, the multivariate analysis also included variables bivariately associated with antibiotic prescription $(P<0.10)$. When there was an overlap between bivariately significant variables regarding patients' history and physical examination (eg, runny nose), we selected the variables obtained during the patients' history-taking, because these were considered to be the most valid for the signs and symptoms at the evening before, that is, the moment of antibiotic prescription. Missing data were considered missing at random or missing completely at random (ie, the missing data were not or only slightly related to the outcome or other known variables) and were imputed using multiple imputation. ${ }^{26}$ Multiple imputation was performed using MICE in R-2.11.1 for Windows.

Frequencies were calculated on the original data, and logistic regression was performed on the imputed data. In the multivariate logistic regression analysis, statistical significance was set at $P<.05$. Calibration of the model was assessed using the Hosmer-Lemeshow test. The proportion of variability in the data set that is accounted for by the statistical model was determined using Nagelkerke $R^{2}$. Data were analyzed using SPSS Version 17.0.2 for Windows (SPSS, Inc, Chicago, IL).

\section{Results}

\section{Description of the Population}

We included 443 children in our analyses (Figure). Two hundred forty-seven (55.8\%) were boys, and the median age of the total group was 20.0 months (range, 3-70 months). Mean rectal temperature at the time of assessment was $37.6^{\circ} \mathrm{C}$ (SD 0.90; median $36.7^{\circ} \mathrm{C}$; range, $34.8-40.0^{\circ} \mathrm{C}$ ). In total, 117 children $(26.5 \%)$ received a prescription for antibiotics at the out-of-hours service. The median duration between consultation of the out-of-hours service and home visit was 14.5 hours (range, 5.4225.4 hours). Additional patient characteristics are presented in Table 1. Only children who had a face-to-face contact with a family physician at the

Figure 1. Flowchart of eligible children. GP, general practice.

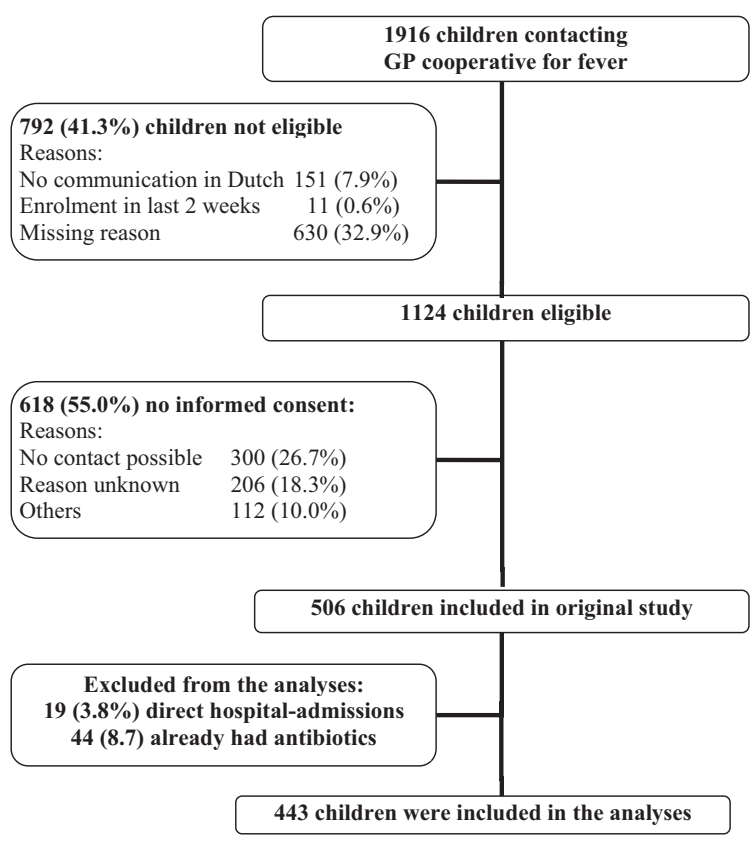


Table 1. Characteristics of the Study

Population $(n=443)$

\begin{tabular}{lcc}
\hline & $\begin{array}{c}\text { No. of Patients/ } \\
\text { Total No. } \\
\text { of Patients }\end{array}$ & Percentage \\
\hline Age: 3 -6 months & $35 / 443$ & 7.9 \\
6-12 months & $87 / 443$ & 19.6 \\
$>12$ months & $321 / 443$ & 72.5 \\
Male sex & $247 / 443$ & 55.8 \\
Rectal temperature $\geq 38.0^{\circ} \mathrm{C}$ & $135 / 419$ & 32.2 \\
Ill appearance & $42 / 436$ & 9.6 \\
Duration of illness in days & 1.00 (median) & 0 to 43 (range)
\end{tabular}

out-of-hours service $(\mathrm{n}=322)$ received a prescription for antibiotics; this occurred in 36.3\% (117 of 322) of the children.

\section{Bivariate Logistic Regression}

Bivariate logistic regression showed that (according to our predefined threshold of $P<.10$ ), the following variables were significantly associated with antibiotic prescription: age 3 to 6 months, concerned parents at the home visit, number of children in the household, duration of illness, fever in the past 6 months, vaccination in the previous week, decreased urine production, increased rectal temperature, ill appearance, Yale Observation Scale score, earache resulting in altered behavioral or sleeping pattern, signs of throat infection, and runny nose (based on patient history and on physical examination; Tables 2 and 3). Of these, 4 variables were based on the patient's history, 3 on physical examination, and one on demographic data.

\section{Multivariate Logistic Regression}

Of the 15 variables included in the multivariate analysis, 8 were based on the expected association and 7 additional on the bivariate significance (Table 2). Signs and symptoms positively associated with antibiotic prescription were concerned parents during the home visit, ill appearance, earache resulting in altered behavioral or sleeping patterns, signs of throat infection, and decreased urine production. A negative association with antibiotic prescription was found for age 3 to 6 months and increased rectal temperature. The model calibrated well: median $\mathrm{P}$ value on the Hosmer-Lemeshow test was 0.55 (range, $0.38-0.76$ ). The median Nagelkerke $R^{2}$ was 0.26 (range, $0.24-0.28$ ), indi- cating that only a small proportion of the antibiotic prescriptions is explained by the signs and symptoms.

\section{Discussion}

In the present study, approximately one in 4 children with fever, whose parents contacted the outof-hours service, and who were not referred or already used antibiotics at initial presentation, received an antibiotic prescription. All antibiotics were prescribed during face-to-face contact with the family physician: approximately $36 \%$ of the children with this type of contact were prescribed antibiotics. In the multivariate analysis, several signs and symptoms were significantly related to antibiotic prescription, providing insight into the family physicians' decision-making process when assessing children with fever. Signs and symptoms, however, explained only a small proportion of the antibiotic prescriptions.

In the present study, the amount of prescribed antibiotics was high, especially when you consider that we excluded 44 children of our analysis who were already using antibiotics, so the total amount of antibiotic use is even higher (ie, 161 of 506 [31.8\%]). In comparison with the United States, and other European countries, Dutch family physicians have one of the lowest overall rates of antibiotic prescriptions. ${ }^{21,27}$ In The Netherlands, Otters et $\mathrm{al}^{19}$ investigated the antibiotic prescription in children per family physician contact and found that (in our age-group of $\leq 6$ years) approximately $12 \%$ was prescribed an antibiotic. However, their percentage was based on all consultations, not solely on those concerning children with fever, and also included regular office hours. Other studies also described antibiotic prescription rates, but differences in the characteristics of the study population (eg, only children with AOM, not solely febrile children $)^{27-30}$ complicate comparison.

An explanation for the considerable amount of antibiotic prescriptions in the present study could be that only children who contacted an out-of hours service were included. These children may be more seriously ill than those seen during regular office hours and therefore more eligible for antibiotic treatment. However, it seems unlikely that this selection of patients leads to more infections caused by bacteria, because the severity of illness is not solely determined by the causative agent. In addi- 


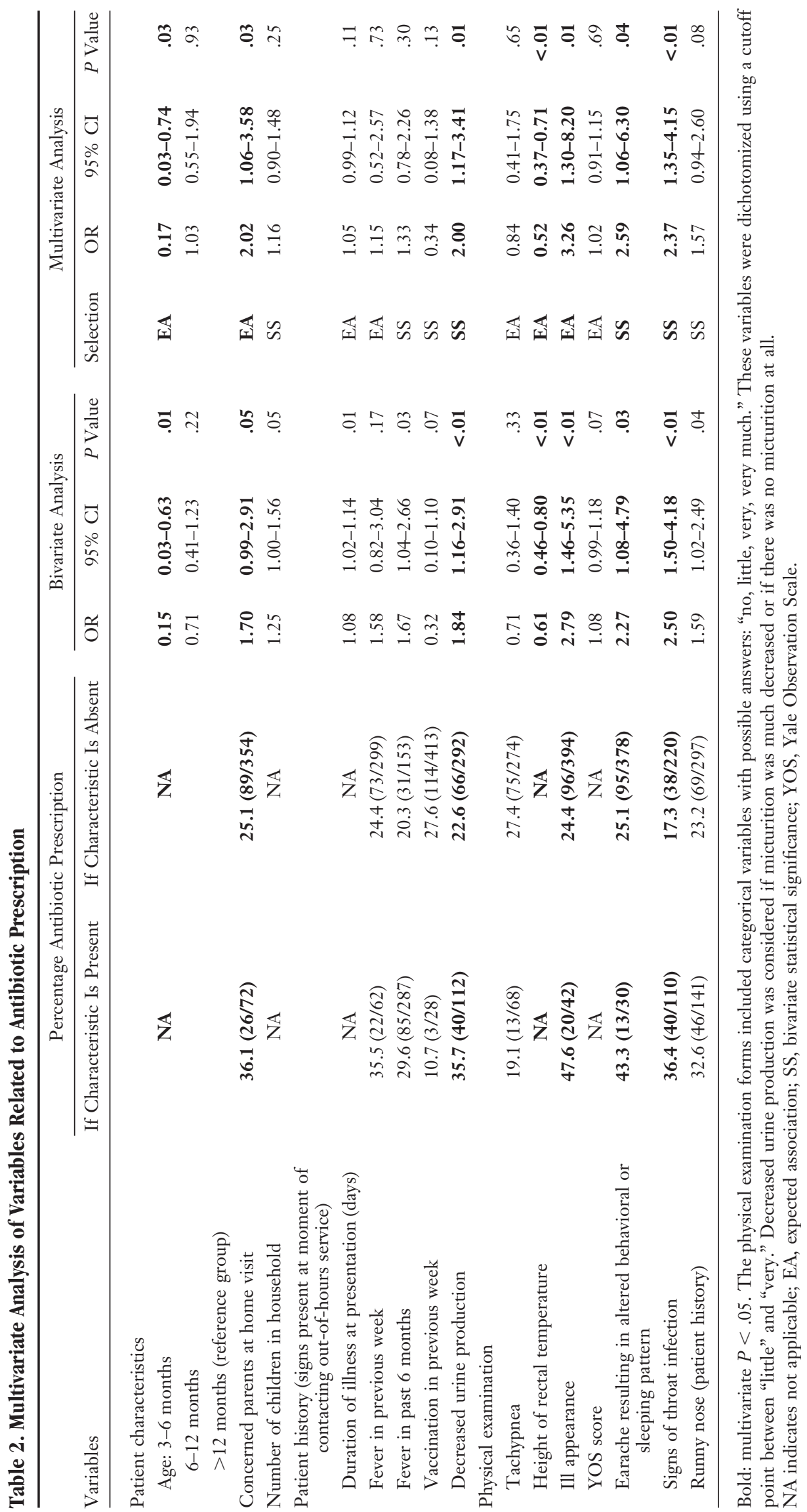


Table 3. Bivariate Analysis of Variables Not Included in the Multivariate Analysis of Antibiotic Prescription

\begin{tabular}{|c|c|c|}
\hline Variables & OR & $95 \% \mathrm{CI}$ \\
\hline \multicolumn{3}{|l|}{ Triage } \\
\hline Concerned parents during triage & 1.17 & $0.70-1.93$ \\
\hline \multicolumn{3}{|l|}{ Physical examination } \\
\hline Coughing & 1.34 & $0.87-2.08$ \\
\hline Runny nose & 2.07 & $1.32-3.23$ \\
\hline Drooling & 1.33 & $0.79-2.23$ \\
\hline Nasal flaring during breathing & 1.11 & $0.12-10.64$ \\
\hline Capillary refill $>2$ seconds & 1.45 & $0.63-3.33$ \\
\hline Abnormalities of the skin & 0.74 & $0.45-1.22$ \\
\hline Lymph nodes palpable in neck & 0.95 & $0.61-1.48$ \\
\hline Not able to get chin on chest & 1.55 & $0.42-5.77$ \\
\hline \multicolumn{3}{|l|}{ Patient history (signs present at moment of contacting out-of-hours service) } \\
\hline Temperature measured at home before contacting the out-of-hours service & 0.63 & $0.32-1.22$ \\
\hline Child previously seen by own family physician & 1.26 & $0.68-2.33$ \\
\hline Out-of-hours service repeatedly contacted & 0.84 & $0.38-1.83$ \\
\hline Diarrhea & 0.93 & $0.56-1.54$ \\
\hline Vomiting & 1.25 & $0.80-1.96$ \\
\hline Drowsy/difficult to wake & 1.41 & $0.92-2.16$ \\
\hline Pale/gray/spotted skin & 1.41 & $0.92-2.16$ \\
\hline Skin rash & 0.82 & $0.48-1.42$ \\
\hline Fast breathing & 1.44 & $0.93-2.23$ \\
\hline Moaning & 0.89 & $0.58-1.36$ \\
\hline Febrile seizure & 0.59 & $0.19-1.77$ \\
\hline Problems during previous febrile episode & 1.19 & $0.71-1.99$ \\
\hline Preterm labor & 0.81 & $0.45-1.46$ \\
\hline Under treatment of a pediatrician & 0.67 & $0.36-1.26$ \\
\hline Under treatment of an ear, nose, and throat physician & 1.33 & $0.56-3.16$ \\
\hline Received all recommended vaccinations & 1.49 & $0.41-5.37$ \\
\hline Language barrier & 1.44 & $0.67-3.07$ \\
\hline Played as usual & 0.80 & $0.51-1.23$ \\
\hline Drinking less than half than normal & 1.09 & $0.70-1.70$ \\
\hline Cough & 1.17 & $0.74-1.84$ \\
\hline Restless/confused & 0.99 & $0.62-1.58$ \\
\hline Irritable/irritated & 1.14 & $0.73-1.76$ \\
\hline Drooling & 0.95 & $0.55-1.65$ \\
\hline Different illness than usual & 1.21 & $0.78-1.88$ \\
\hline Eye contact & 1.10 & $0.60-2.03$ \\
\hline Inconsolable crying & 1.23 & $0.80-1.88$ \\
\hline Crying by picking up & 1.14 & $0.72-1.81$ \\
\hline \multicolumn{3}{|l|}{ Demographic data } \\
\hline Sex (if male) & 1.27 & $0.83-1.95$ \\
\hline Country of birth of mother, not Dutch & 1.29 & $0.84-1.97$ \\
\hline Country of birth of father, not Dutch & 0.81 & $0.53-1.24$ \\
\hline Education of mother: high & 0.95 & $0.56-1.59$ \\
\hline Education of father: high & 1.10 & $0.69-1.76$ \\
\hline Ethnicity of child according to parents, not Dutch & 1.13 & $0.72-1.78$ \\
\hline Income & 1.08 & $0.92-1.26$ \\
\hline
\end{tabular}

Bold: $P<.10$. The history and physical examination forms included categorical variables with possible answers: "no, little, very, very much." These variables were dichotomized using a cutoff point between "little" and "very." Categorical variables with possible answers: "no, little, almost normal, normal" were dichotomized using a cutoff point between "no" and "little." Diarrhea was characterized as reported diarrhea more than twice a day. Decreased urine production was considered if micturition was much decreased or if there was no micturition at all. Income was categorized before the analysis in net income per month: "<450," "451 to 635 ," "636 to 860," "861 to 1135," "1136 to 1600," "1601 to 2270," ">2270 Euro." CI, confidence interval; OR, odds ratio. 
tion, because only a small proportion of the antibiotic prescription is explained by the reported signs and symptoms, other considerations may have contributed substantially.

Also, in The Netherlands, children and their families are all registered at one family physician, who usually knows the child from previous visits. However, as a result of the organization of out-ofhours primary care, family physicians in The Netherlands are generally not familiar with the patients they see at the out-of-hours service. Therefore, assessing the patient's expectations and providing adequate safety netting is more difficult. This could make managing the child's disease during out-ofhours service more difficult, leading to a more defensive treatment and, thus, to more antibiotic prescription.

The signs and symptoms that were multivariately related to antibiotic prescription can be clearly related to distinct disease profiles (ie, rhinosinusitis, tonsillitis, AOM). It was not our objective to judge whether the prescribed antibiotics were legitimate for individual cases, but rather to identify and discuss which factors may play a role in the family physicians' decision-making process.

In the multivariate analysis, earache resulting in altered behavioral/sleeping patterns and signs of throat infection are significantly related to antibiotic prescription (OR, 2.58; 95\% CI, 1.05-6.33 and OR, 2.53; 95\% CI, 1.44-4.43, respectively). These can be related to the disease profiles for $\mathrm{AOM}$ and tonsillitis, for which the Dutch guidelines for family physicians have clear recommendations for antibiotic prescription under certain conditions. ${ }^{6,9}$ In these guidelines, the rationale for giving antibiotic treatment is mainly based on the possible reduction of duration and severity of illness. ${ }^{14,15}$ Therefore, this seems to play an important role in the decision-making process of the family physicians.

In the bivariate and multivariate analyses, both ill appearance and parental concern as assessed by the research nurse were significantly associated with increased antibiotic prescription. Respectively, $47.6 \%$, and $36.1 \%$ of the children had received antibiotics. Ill appearance is similar, although not identical, to the physician's opinion that "something is wrong." This and parental concern have been shown to be important red flags in identifying children with serious infections in primary care. ${ }^{31}$ Therefore, it seems rational to pre- scribe antibiotics for febrile children who appear to be ill or have concerned parents. Because the home visit was performed after the family physician's consultation, the research nurse might have assessed the child with antibiotics as more severely ill simply because the family physician had prescribed antibiotics. Also, she might have judged the parents as more concerned. However, the research nurses were not aware of the research question; thus, it seems unlikely that this has led to important bias.

Decreased urine production was bivariately and multivariately associated with antibiotic prescription. Although this symptom indicates dehydration, none of the Dutch (or international) guidelines describes dehydration in children as an indication for antibiotic treatment. ${ }^{24,32}$ Therefore, it seems that, in at least a subgroup of our patients, antibiotics were not prescribed appropriately.

Children in the age of 3 to 6 months and children with increased rectal temperature were associated with decreased antibiotic prescription. For logistic reasons, we did not include the children who were admitted to the hospital directly after their visit to the out-of-hours service $(n=19)$. This seems to have introduced some selection bias, leading to these surprising findings. For instance, the children admitted to hospital were younger (median age, 15 months; range, 3-66 months) versus 20 months in the children included in our analysis (range, 3-70 months), and it could be that they also had a higher rectal temperature (data not known) and may have received antibiotics but were not included in our analyses.

A further limitation is that the research nurse noted the patient's history and made the physical examination the day after the patient had contact with the out-of-hours service. We chose this study design, because we did not want to interfere with regular care of the out-of-hours service (especially in case of telephone advice without face-to-face contact). However, the research nurse specifically asked for the signs that were present at time of consultation of the out-of-hours service. In addition, the median time elapsed between time of consultation of the out-of-hours service and our home visit was only 14.5 hours. Given this short delay, it is unlikely that the antibiotic treatment started after the family physician consultation influenced our findings by physical examination, because it generally takes longer to show an effect 
than the interval we allowed between the family physician consultation and our data collection. ${ }^{33}$

Only a small proportion of the antibiotic prescriptions is explained by the related signs and symptoms. Although our study does not allow further exploration of these unknown factors, it does indicate that other, nonmedical factors may influence the family physicians in their decision to prescribe antibiotics. This is in clear contrast with the national and international guidelines that solely base their recommendations to prescribe antibiotics on medical considerations. ${ }^{4-7,18}$ Previous studies have also shown that other (not medically based) considerations may play a role in the family physician's decision to prescribe antibiotics (eg, assuming that the patient or the parents expect antibiotics). ${ }^{10-12}$ In our study, we show that a substantial amount of the antibiotic prescriptions is prescribed on the basis of these considerations.

\section{Conclusions}

This study revealed a substantial amount of antibiotic prescriptions. Not all signs and symptoms associated with antibiotic prescription are in accordance with national and international guidelines for serious illness. It seems that the aim to decrease the duration and severity of the symptoms also plays a considerable role in the decision to prescribe antibiotic treatment. Moreover, because only a small proportion of the antibiotic prescriptions is explained by these signs and symptoms, other (nonmedically based) considerations may have played a role in the family physician's decision to prescribe antibiotics. However, because serious infections are rare in primary care, and most febrile illnesses are self-limiting, family physicians need to reflect on the legitimacy of their considerations regarding antibiotic treatment. Strategies that may diminish antibiotic prescriptions (eg, safety netting) need to be further explored.

We thank the parents of the children who participated in this study, the receptionists of the GP cooperative in RotterdamSouth, Berth J. Broekman (manager GP cooperative South), and Eef van Dijk, director of the Central GP cooperatives Rijnmond.

\section{References}

1. Bruijnzeels MA, Foets M, van der Wouden JC, van den Heuvel WJ, Prins A. Everyday symptoms in childhood: occurrence and general practitioner consultation rates. Br J Gen Pract 1998;48:880-4.

2. Van den Bruel A, Bartholomeeusen S, Aertgeerts B, Truyers C, Buntinx F. Serious infections in children: an incidence study in family practice. BMC Fam Pract 2006;7:23.

3. Berger MY, Boomsma LJ, Albeda FW, Dijkstra RH, Graafmans TA, Van der Laan JR, et al. The standard of the Dutch College of General Practitioners on children with fever. Huisarts en Wetenschap 2008; 51:287-96.

4. Baraff LJ, Bass JW, Fleisher GR, Klein JO, McCracken GH Jr, Powell KR, et al. Practice guideline for the management of infants and children 0 to 36 months of age with fever without source. Agency for Health Care Policy and Research. Ann Emerg Med 1993;22:1198-210.

5. Luszczak M. Evaluation and management of infants and young children with fever. Am Fam Physician 2001;64:1219-26.

6. Damoiseaux RAMJ, Van Balen FAM, Leenheer WAM, Kolnaar BGM. The standard for acute otitis media in children of the Dutch College of Genera Practitioners: Second revision. Huisarts en Wetenschap 2006;49:615-21.

7. De Sutter A, Burgers JS, De Bock GH, Dagnelie CF, Labots-Vogelesang SM, Oosterhuis WW, et al. Standard for rhinosinusitis of the Dutch College of General Practitioners-Second revision. Huisarts en Wetenschap 2005;48:615-24.

8. Verheij TIM, Salome PL, Bindels PI, Chavannes AW, Ponsioen BP, Sachs APE, et al. Standard for acute cough of the Dutch Association for General Practitioners. Huisarts en Wetenschap 2003;46: 496-506.

9. Zwart S, Dagnelie CF, Van Staaij BK, Balder FA, Boukes FS, Starreveld JS. Standard on acute sore throat of the Dutch College of General Practitioners-Second revision. Huisarts en Wetenschap 2007;50:59-68.

10. Anon JB, Jacobs MR, Poole MD, Ambrose PG, Benninger MS, Hadley JA, et al. Antimicrobial treatment guidelines for acute bacterial rhinosinusitis. Otolaryngol Head Neck Surg 2004; 130(suppl): $1-45$.

11. Wong DM, Blumberg DA, Lowe LG. Guidelines for the use of antibiotics in acute upper respiratory tract infections. Am Fam Physician 2006;74: 956-66.

12. Bisno AL, Gerber MA, Gwaltney JM Jr, Kaplan EL, Schwartz RH. Practice guidelines for the diagnosis and management of group A streptococcal pharyngitis. Infectious Diseases Society of America. Clin Infect Dis 2002;35:113-25.

13. American Academy of Pediatrics Subcommittee on Management of Acute Otitis Media. Diagnosis and management of acute otitis media. Pediatrics 2004; 113:1451-65. 
14. Del Mar CB, Glasziou PP, Spinks AB. Antibiotics for sore throat. Cochrane Database Syst Rev 2000; 4:CD000023.

15. Rovers MM, Glasziou P, Appelman CL, Burke P, McCormick DP, Damoiseaux RA, et al. Antibiotics for acute otitis media: a meta-analysis with individual patient data. Lancet 2006;368:1429-35.

16. Akkerman AE, Kuyvenhoven MM, van der Wouden JC, Verheij TJ. Determinants of antibiotic overprescribing in respiratory tract infections in general practice. J Antimicrob Chemother 2005;56:930-6.

17. Akkerman AE, Kuyvenhoven MM, van der Wouden JC, Verheij TJ. Analysis of under- and overprescribing of antibiotics in acute otitis media in general practice. J Antimicrob Chemother 2005;56:569-74.

18. Welschen I, Kuyvenhoven M, Hoes A, Verheij T. Antibiotics for acute respiratory tract symptoms: patients' expectations, GPs' management and patient satisfaction. Fam Pract 2004;21:234-7.

19. Otters HB, van der Wouden JC, Schellevis FG, van Suijlekom-Smit LW, Koes BW. Trends in prescribing antibiotics for children in Dutch general practice. J Antimicrob Chemother 2004;53:361-6.

20. Jansen AG, Sanders EA, Schilder AG, Hoes AW, de Jong VF, Hak E. Primary care management of respiratory tract infections in Dutch preschool children. Scand J Prim Health Care 2006;24:231-6.

21. Goossens H, Ferech M, Vander Stichele R, Elseviers M. Outpatient antibiotic use in Europe and association with resistance: a cross-national database study. Lancet 2005;365:579-87.

22. Jacobs MR, Dagan R. Antimicrobial resistance among pediatric respiratory tract infections: clinical challenges. Semin Pediatr Infect Dis 2004;15:5-20.

23. Telefoonwijzer. Nederlands Huisartsen Genootschap. NHG-TelefoonWijzer: een leidraad voor triage en advies. Utrecht, The Netherlands: NHG; 2007.

24. Richardson M, Lakhanpaul M. Assessment and initial management of feverish illness in children younger than 5 years: summary of NICE guidance. BMJ 2007;334:1163-4.

25. McCarthy PL, Sharpe MR, Spiesel SZ, Dolan TF, Forsyth BW, DeWitt TG, et al. Observation scales to identify serious illness in febrile children. Pediatrics 1982;70:802-9.

26. Donders AR, van der Heijden GJ, Stijnen T, Moons KG. Review: a gentle introduction to imputation of missing values. J Clin Epidemiol 2006;59:1087-91.

27. Rossignoli A, Clavenna A, Bonati M. Antibiotic prescription and prevalence rate in the outpatient paediatric population: analysis of surveys published during 2000-2005. Eur J Clin Pharmacol 2007;63: 1099-106.

28. Lusini G, Lapi F, Sara B, Vannacci A, Mugelli A, Kragstrup J, et al. Antibiotic prescribing in paediatric populations: a comparison between Viareggio, Italy and Funen, Denmark. Eur J Public Health 2009;19: 434-8.

29. Plasschaert AI, Rovers MM, Schilder AG, Verheij TJ, Hak E. Trends in doctor consultations, antibiotic prescription, and specialist referrals for otitis media in children: 1995-2003. Pediatrics 2006;117: 1879-86.

30. Finkelstein JA, Metlay JP, Davis RL, Rifas-Shiman SL, Dowell SF, Platt R. Antimicrobial use in defined populations of infants and young children. Arch Pediatr Adolesc Med 2000;154:395-400.

31. Van den Bruel A, Aertgeerts B, Bruyninckx R, Aerts M, Buntinx F. Signs and symptoms for diagnosis of serious infections in children: a prospective study in primary care. Br J Gen Pract 2007;57:538-46.

32. Brühl PC, Lamers HJ, Van Dongen AM, Lemmen WH, Graafmans D, Jamin RH, et al. Standard of the Dutch College of General Practitioners for acute diarrhea. Huisarts en Wetenschap 2007;50:103-13.

33. Spurling GKP, Del Mar CB, Dooley L, Foxlee R. Delayed antibiotics for respiratory infections. Cochrane Database Syst Rev 2007;3:CD004417. 